\title{
Meckel's Diverticulum in a Minor Omphalocele
}

\author{
Van Ginkel DJ*, Zwart K, Hulsker CCC, Tytgat SH, Van der Zee DC \\ Department of Pediatric Surgery, University Medical Center Utrecht, The Netherlands
}

*Corresponding author: Van Ginkel DJ, Department of Pediatric Surgery, Wilhelmina Children's Hospital, University Medical Center Utrecht, Heidelberglaan 100, 3584CX, Utrecht, Netherlands

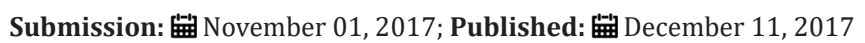

\section{Introduction}

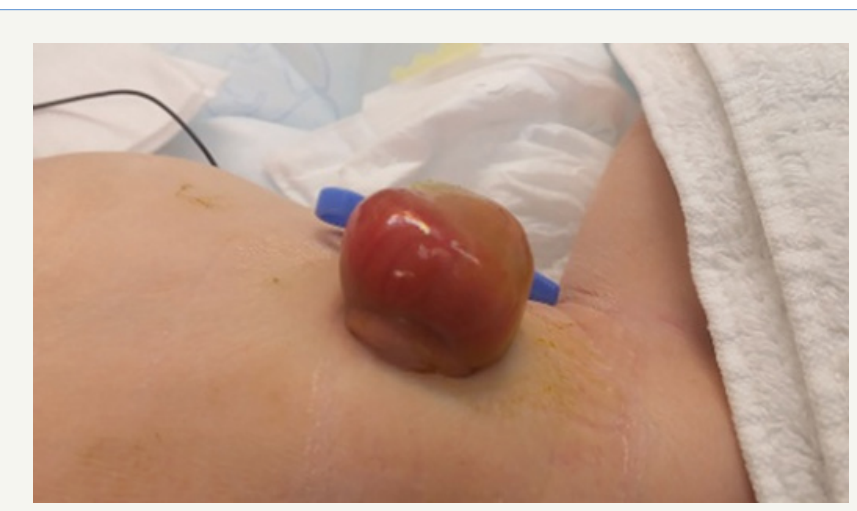

Figure 1: $3 \times 2,5 \times 4 \mathrm{~cm}$ size minor omphalocele through which a segment of bowel is clearly visible.

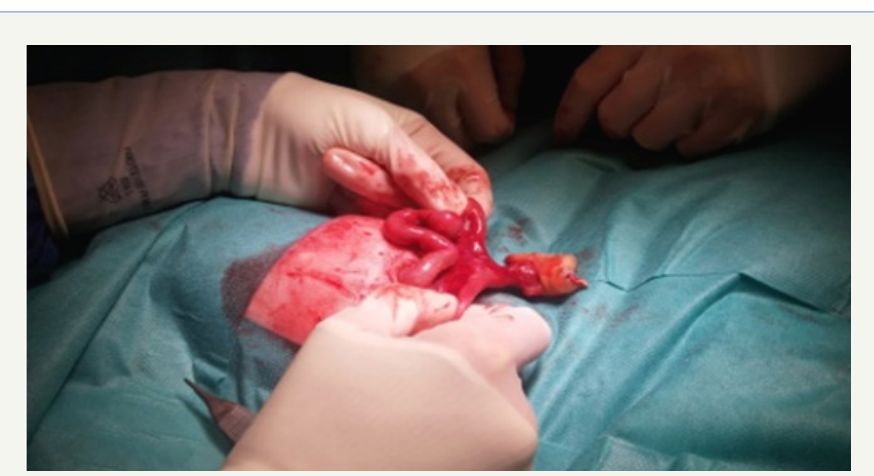

Figure 2: During inspection of the contents of the omphalocele a Meckel's diverticulum was found.

A full-term female neonate presented post-partum with an antenatally undetected minor omphalocele after an uncomplicated pregnancy (Figure 1). No other congenital abnormalities were identified upon evaluation. Surgery of the $3 \times 2,5 \times 4 \mathrm{~cm}$ omphalocele was performed eight hours post-delivery. Opening the omphalocele sac revealed an additional abnormality, namely a Meckel's diverticulum (Figure 2). Subsequently, resection of the Meckel's diverticulum with minimal ileal resection and end-to-end anastomosis was performed. After reduction of the bowel into the abdominal cavity, the abdominal wall was closed with formation of a neo-umbilicus (Figure 3). Further histopathological analysis of the resected tissue confirmed a Meckel's diverticulum with locally active inflammation.

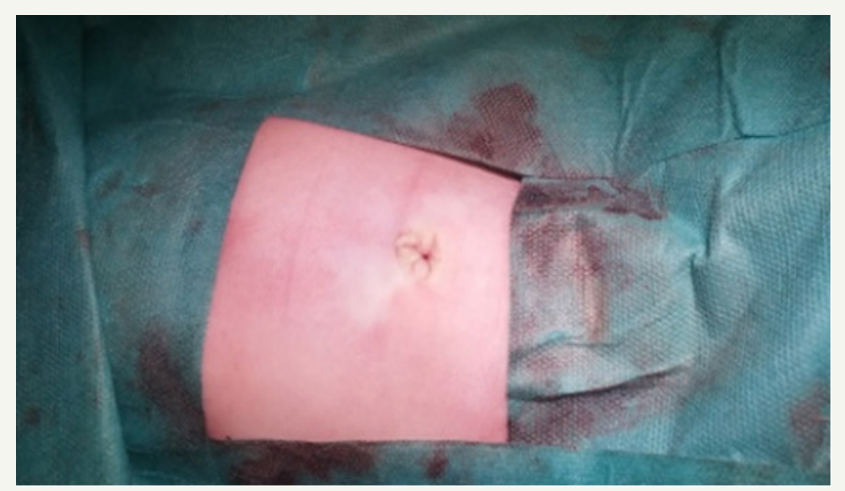

Figure 3: The neo-umbilicus.

An omphalocele is a congenital midline abdominal wall defect, that results in herniation of intra-abdominal contents through the umbilical orifice covered by a lining of peritoneum and amnion, with a prevalence of 1,92 per 10000 live births [1]. The literature distinguishes between a minor and major omphalocele (minor $<4$ $\mathrm{cm}$, major $>4 \mathrm{~cm}$ abdominal wall defect) which occur in a ratio of $1: 1[2]$.

A Meckel's diverticulum is a congenital diverticulum of the ileum, caused by the incomplete regression of the omphalo-enteric duct, with a prevalence of 2 per 100 live births [3].

According to the literature, the incidence of a Meckel's diverticulum as an associated abnormality in major omphaloceles seems similar to the normal population $[2,4]$. The incidence rate of a Meckel's diverticulum in a minor omphalocele,however,is remarkably high, varying from $15 \%$ up to $28 \%[2,4]$. This underlines the importance of careful inspection of the contents of a minor omphalocele sac before reducing the bowel into the abdominal cavity.

The presence of a Meckel's diverticulum might be associated with the development of a minor omphalocele, as opposed to a major omphalocele. A patent omphalo-enteric duct could cause a small closure defect of the umbilicus, creating a minor omphalocele 
or herniation of the umbilical cord. This newly proposed theory could explain the aetiology as well as the high incidence rate of a Meckel's diverticulum in a minor omphalocele.

\section{References}

1. Marshall J, Salemi JL, Tanner JP, Ramakrishnan R, Feldkamp ML, et al. (2015) Prevalence, Correlates, and Outcomes of Omphalocele in the United States, 1995-2005. Obstet Gynecol 126(2): 284-293.
2. Kumar HR, Jester AL, Ladd AP (2008) Impact of omphalocele size on associated conditions. J Pediatric Surg 43(12): 2216-2219.

3. Yahchouchy EK, Marano AF, Etienne JF, Fingerhut AL (2001) Meckel's diverticulum. J Am Coll Surg 192(5): 658-662.

4. Nicol JW, MacKinlay GA (1994) Meckel's diverticulum in exomphalos minor. J R Coll Surg Edinb 39(1): 6-7. 